\title{
MANIFIESTO POR UN JURADO PÚBLICO, SOBERANO Y COMPETENTE
}

\section{MANIFEST FOR PUBLIC JURY, SOVEREIGN AND COMPETENT}

Joaquín González López: AJURA (Asociación de apoyo al Jurado Público). ajura-ong@terra.es

\section{RESUMEN}

La Justicia penal tiene pendiente la asignatura de democratización, se ha quedado vieja. Se rige por una Ley de 1882, la Ley de Enjuiciamiento Criminal. Es la ley que más modificaciones ha sufrido a lo largo de los años, y ningún gobierno ha conseguido derogarla. Pero esta ley no es de la sociedad, es el instrumento punitivo del Estado, y como tal tiene dos beneficios: los jueces y la atribución de un preproceso. La única modificación que se ha incluido en beneficio de la sociedad es la institución del Jurado Público.

\section{PALABRAS CLAVE}

Justicia Penal - Ley - Jueces - Jurado Público

\section{ABSTRACT}

Criminal Justice is pending subject of democratization, has been old. It is governed by an Act of 1882, the Criminal Procedure Act. Is the law that has undergone more changes over the years, and no government has managed to repeal it. But this law is not of the society, the State's punitive instrument, and as such has two benefits: the 
judges and the assignment of a pre-processing. The only modification has been included for the benefit of society is the institution of the Public Jury.

\section{KEY WORDS}

Criminal Justice - Law - Judges - Public Jury

\section{TEXTO:}

La Justicia penal, en España, se ha quedado vieja. De hecho, se rige por una Ley de 1882. Se trata de un cuerpo legal fosilizado en el tiempo que ha resistido todos los embates de la Historia hasta hoy y que la Constitución de 1978 no ha logrado derogar. Estamos hablando de la Ley de Enjuiciamiento Criminal (LECr). Todas las leyes básicas del Estado de Derecho han dado a luz textos modernizados y adaptados a las exigencias de los Derechos Humanos, Civiles y Políticos. La LECr, en su espina dorsal, se ha mantenido incólume. Seguramente debe ser la Ley que más modificaciones ha sufrido y que, seguramente, seguirá sufriendo más con el paso del tiempo. Durante sus 121 años de vida ningún Gobierno, de derechas, de centro o de izquierdas se ha planteado su derogación sustituyéndola por un texto nuevo y moderno. En resumen: la LECr. ha resistido a todos los regímenes políticos. En conclusión: la Justicia penal tiene pendiente la asignatura de democratización.

Por su longevidad se podría llegar a pensar que es tan buena, y tan válida, que merece conservarse. No es así. La LECr. es, en realidad, el instrumento punitivo del Estado, que no de la sociedad. Como tal, fundamentalmente es una Ley de privilegios. 
El primero de ellos es que son los jueces, unipersonales o colegiados, los que tienen el poder omnímodo para determinar, antes de abrir cualquier causa, lo que es delito y lo que no lo es (Art. 313). Este es el privilegio de pre-juzgar sin ni siquiera entrar a conocer.

El segundo, es la atribución de un pre-"proceso" que es la Instrucción. Esta institución representa la llave de la puerta del proceso, de cualquier causa o imputación. La misma está asignada, por lo general, a un Juez unipersonal que decide la preparación de las pruebas de cargo contra el acusado, con cierta colaboración de la policía, las sugerencias telegráficas del $\mathrm{M}^{\mathrm{o}}$ Fiscal y la participación de las partes que tienen, en realidad, muy limitada su actuación pues las determinaciones principales son criterio, y arbitrio, del Juez de Instrucción. Después, esa causa es juzgada por otro Juez, unipersonal o colegiado, vinculado a la Instrucción, en una vista pública que, gracias a la Constitución, las partes están amparadas mayormente por ciertas garantías.

Pues bien, durante 121 años las modificaciones substanciales a estos privilegios han sido dos pero de signo contrapuesto:

La principal es la institución del Jurado Público para juzgar cierto tipo de delitos graves, entre los que no figura la acción penal por delito de prevaricación contra Jueces y Magistrados. No obstante, más del 95 \% de los procesos penales están fuera de la órbita del Jurado. La Ley del Jurado se aprobó, en su día, a contrapelo de los partidos conservadores y, sobre todo, del Poder Judicial que veía en esta Institución el Caballo de Troya contra sus privilegios y corporativismo, es decir, como peligrosa amenaza. De hecho, en nuestra Historia coincide el Jurado Público con las épocas de regímenes progresistas y su derogación con los conservadores o dictatoriales. Esto no quiere decir que, hoy, en la corporación judicial no existan miembros convencidos de la necesidad del Jurado Público. 
De signo opuesto están hoy, en los vientos que corren de legislar al albur de una alarma social industrializada y mediatizada, la suma de privilegios para reforzar, y fortalecer, el papel unipersonal del Juez de Instrucción atribuyéndole unas facultades de excepción para acelerar la instrucción en tiempos record y, por otra parte, para juzgar la determinación de medidas cautelares que afectan a los intereses vitales y fundamentales de las personas. Son las llamadas leyes urgentes de "genero", cuyo número no ha dejado de progresar, y los juicios veloces que, en realidad, su "mejor" factura es la alta estadística de conformidades del acusado con la imputación ya que así, al menos, se "ahorra" un tercio de la condena nominal y no va a la cárcel. Vana ilusión porque la próxima reforma de la prisión provisional convertirá en un espejismo esa "ventaja".

Luego están lo que podríamos denominar "zancadillas" jurídicas, trabas o baremos que se han impuesto en el régimen de los recursos con el único objetivo de aplicar la tijera a la funesta manía de los españoles, (parafraseando a D. Fernando VII...que en paz descanse),de recurrir por recurrir cualquier resolución judicial. Hay que esperar que esta tendencia no remita, en absoluto.

Sin embargo, los hechos suelen ser tozudos, poco fáciles de persuadir que sean de otra manera $\mathrm{y}$, aunque se pueden manipular todos durante un tiempo, con todos ellos no se puede engañar a un pueblo durante todo el tiempo. Los hechos dicen que la llamada Administración de Justicia sencillamente no funciona, cada día hay más conflictividad social y más gente descontenta, produciéndose progresivamente fenómenos sociales, dementes, salvajes y bárbaros, tan complejos que tienen difícil tratamiento jurídico o represivo, aunque la factura por estos conceptos no deje de aumentar. 
Baste una breve estadística real sobre los tozudos hechos. De principio, y a modo genérico, la estadística comparativa ( pasado y presente) de asuntos relacionados con la Administración de Justicia no ha dejado, año tras año, de dispararse en aumento, que no en retroceso. Los 7 millones de pleitos que se instaron en 2002, contienen un aumento del $5 \%$ respecto al año anterior. 5 millones fueron penales que, también, sufrieron incremento comparativo anual. Ya este dato es muy ilustrativo.

Según el CIS, en 1992 (última encuesta) sólo era posible encontrar un 3 \% de españoles que afirmaban que los jueces les inspiraban mucha confianza. Al 12 \% no les inspiraba ninguna confianza y, entre los de "regular" y poca sumaban el 55 \%. En la misma fecha, y sobre la imparcialidad de los Jueces, también un 55 \% puso en duda esa virtud judicial. $Y$, finalmente, respecto al funcionamiento de la maquinaria judicial el $7 \%$ decía que mal y fatal el 31 y $7 \%$, respectivamente, y un $26 \%$ que "regular". No obstante, entonces, un 17 \% de españolitos, todavía, no opinaba sobre esta última cuestión. Sería interesante disponer de los datos, al respecto, en 2003... ¡Paciencia, llegará...!

Si hablamos de registros, nada mejor que mirar los del Tribunal Constitucional ya que éste es el último eslabón desesperado de la cadena impugnativa. En 1999 al Alto Tribunal amparador de los derechos fundamentales de los españoles le llegaron 5.651 recursos ( 5.582 propiamente de amparo). De éstos, sólo se admitieron iii224!!!....Debe tenerse en cuenta que el $42 \%$ de los recursos de amparo provenían de la jurisdicción penal. Ya se sabe que la mayoría de los recursos de amparo los interponen personas particulares.

Un dato ilustrativo es que el 74, 96 de los recursos de amparo presentados lo fueron por presunta vulneración de la tutela judicial efectiva y, por ejemplo, el 12, 49 \% lo fueron para reivindicar el principio de presunción de inocencia. 
Pues bien, en el 2002 el T.C. recibió 7.456 recursos, el 97, 71 \% lo fueron de amparo y se admitieron iii179!!!. Ahora bien, la admisión nada tiene que ver con la resolución definitiva, pero es fácil imaginar que se cuentan con los dedos de la mano los que obtuvieron resolución favorable.

Cerrando la estadística instructiva, ésta " cojea", ¡obviamente!, en ofrecer datos a los españoles sobre los registros de las demandas, de particulares, por responsabilidad patrimonial del Estado, por mal funcionamiento de la Admón. de Justicia o por error judicial. Si dispusiéramos de tales datos la radiografía del Poder Judicial nos permitiría poder observar, con un diagnostico más acertado, esta crónica enfermedad. No obstante, los síntomas de la dolencia ofrecen pocas dudas de la necesidad de administrar la medicina a una Justicia anclada en 1882.

Ahora, presenciamos el fenómeno, muy común entre el género humano, de buscar un culpable. ¡La Justicia necesita un culpable! Vivimos unos tiempos en el que los responsables de los desafueros se han aprendido la lección de cómo adoptar el papel de victimas. El último refugio de las víctimas era vivir con esa cualidad, estoicamente. Sin embargo ser victimas implica que hay culpables. Hoy, eso, no se puede permitir. Por tanto, el culpable de males que arrastran desde 1882 es el JURADO PÚBLICO, es decir, una Ley con 8 años de edad, por sus "errores" al juzgar, condenando a una inocente y absolviendo a un bandido. ¡Ya lo dijimos..!, dicen...No hay nada más fácil que vapulear al Jurado Por tanto, hay que poner coto a la licencia y que las aguas vuelvan a sus cauces, ; que es de donde no debían haber salido!. Aprovechando la ocasión el Ministro responsable de la Seguridad dice: " ¡Esto no nos va a volver a ocurrir pues vamos a fichar a todos los sospechosos!".

Solución, dice el C.G.P.J.: 1) repescar para un tribunal de Magistrados profesionales a los justiciables que, ahora son absueltos si, tras 2 juicios con Jurado, no se obtiene un veredicto, y 2) introducir en el Jurado a jueces profesionales. 
En definitiva: convertir una causa en permanente hasta que no se obtenga condena e instituir el ascendiente tutelado de los mismos pero, ahora, con denominación de jurados.

Sin embargo, la realidad es que desde la reinstauración el jurado, en 1996, los primeros estudios de seguimiento concluyeron en un índice de absoluciones y condenas similares a las que se daban en los tribunales profesionales, considerando que, desde esa fecha, los Jurados Públicos, han entendido de 2.400 juicios. Y, esto, es realmente lo que escuece, intentando ocultarlo detrás de la cortina de humo del caso Otegui y Dolores Vázquez.

Esta claro que la Ley del JURADO PÚBLICO hay que reformarla y modificarla. EN ESTO ESTAMOS ABSOLUTAMENTE DE ACUERDO. No se trata de vapulearla sino de someterla a una AUTENTICA REFORMA Y MODIFICACIÓN.

En definitiva, la profesión de juzgar es una actividad laboral de riesgo que no nos parece benevolente dejarla en manos de Jueces y Magistrados porque errar es humano y ven mejor 18 ojos que dos, o seis. Además, es muy duro el dicho bíblico " No juzgues y no serás juzgado". Por estas, y por otras muchas razones, la soberanía y facultad de juzgar debe recaer en el pueblo, es decir, en el JUZGADO PÚBLICO, un colectivo de seres corrientes donde se diluye tamaña responsabilidad. Al fin y al cabo todos son responsables pero ninguno en particular.

Los Jueces y Magistrados deben limitarse a aplicar la Ley, y cuidar que se cumpla, que esto no tiene muchos riesgos y, para eso, nuestros Jueces y Magistrados han estudiado mucho tiempo. A cada uno lo suyo. EL CIUDADANO TIENE DERECHO A PARTICIPAR EN LA ADMINISTRACIÓN DE JUSTICIA PARA CONTRIBUIR A 


\section{EVITAR QUE SE ADMINISTRE LA INJUSTICIA. ES UN DERECHO FUNDAMENTAL Y VITAL.}

CONCLUSIONES FINALES: Evidentemente sería muy pretencioso que las primeras Asociaciones que firmamos este manifiesto ofrezcamos la receta de cómo se debe reformar y modificar la LEY DEL JURADO PÚBLICO pues ello merece un DEBATE PÚBLICO y la necesaria aportación de personas entendidas y sensibilizadas por el derrotero que está tomando la Administración de Justicia. Ahora bien, no sería coherente que los que hemos tomado la iniciativa de redactar el presente no ofreciéramos nuestras sugerencias. Estas son:

$\left.1^{a}\right)$ El Jurado debe ser público, es decir, popular formado por personas corrientes, con unos requisitos mínimos de selección, que garantice su imparcialidad, su sentido común y su ecuanimidad y, colectivamente, tiene que ser representativo del espectro social

$2^{a}$ ) El Jurado no tiene porque juzgar a sus convecinos ya que, ello, en la práctica constituye un inconveniente en orden a la imparcialidad, es decir, puede trasladar su función a otra localidad.

$\left.3^{\mathrm{a}}\right)$ El jurado no tiene porque motivar sus veredictos ya que no es su papel. Son los jueces profesionales los que deben asumir la motivación legal de la sentencia.

$4^{a}$ ) No es incompatible con la naturaleza de la institución, ni con su finalidad, que, en una primera fase, esté formado por voluntarios que guarden los requisitos de elección y tenga cierta permanencia en el tiempo sin que, en ningún caso, pueda darse la circunstancia de profesionalización. 
$5^{\text {a) }}$ El Jurado tiene que ser soberano y ello exige que tenga competencia para juzgar los delitos que disponga la ley sin discriminación respecto a los presuntos autores.

$\left.6^{a}\right)$ La institución del Jurado tiene que estar dotada de los suficientes y adecuados medios que permita la dedicación y que la pertenencia al mismo no suponga un perjuicio aquellos que lo constituyen.

7a) El Jurado debe ser competente y, por tanto, sujeto a formación, mediante cursos adecuados a su función. No sabemos si escabinado o escandinavo pero sí, en su selección deben incluirse personas con formación jurídica sin necesidad de que se introduzca a jueces profesionales que derivaría en una tutela inadmisible por su inevitable ascendente. Estamos convencidos de que la sociedad es tan diversa como para poder ser cantera de colectivos con aceptable nivel de calidad.

$8^{a}$ ) El Jurado tiene que estar asistido, de manera multi- disciplinar, por profesionales que abarquen todas las áreas de ayuda a su función.

9a) La transición hacia un verdadero Jurado público, soberano y popular no podrá darse con éxito si no se acomete la reforma del estatuto del $\mathrm{M}^{\circ}$ Fiscal, dotándolo de autonomía y de medios, bastantes y suficientes, para que pueda ejercer su función de acusador público responsable, lo que obliga a capacitarlo con personal y técnicas de investigación, y mediante la vinculación al mismo de un cuerpo de Policía Judicial especializado y con dedicación exclusiva. El $\mathrm{M}^{\circ}$ Fiscal puede estar vinculado a la política judicial del Gobierno, pero su elección y funcionamiento debe estar controlado por el Parlamente y su estatuto de autonomía.

$10^{\mathrm{a}}$ ) Debe promulgarse una Nueva Ley de Enjuiciamiento Criminal, adaptada a las exigencias de nuestro tiempo (2003), con los imprescindibles procedimientos garantizando los derechos fundamentales del ciudadano y que permita el desarrollo 
de los procesos con agilidad sin merma de seguridad jurídica. Por tanto, deberá desaparecer el actual Juzgado de Instrucción, con las competencias que tiene desde 1882, siendo, fundamentalmente, el papel del Juez de Instrucción que la investigación y la imputación se realice con las garantías debidas.

$11^{a}$ ) Es ante el Jurado Público donde se deben presentar las pruebas, de cargo y de descargo, en un juicio oral público, en unidad de acto restringiendo las pruebas preconstituidas pues solo el oral constituye el verdadero juicio, con plena libertad de las partes y siendo el Presidente del Tribunal al que le incumbe que se respete las exigencias de un juicio legal, limpio y justo.

12 $2^{a}$ Como garantía para el ciudadano de que la Administración de Justicia debe tener un buen funcionamiento tiene que promulgarse la Ley de Responsabilidad del Estado por la Administración de Justicia, que contenga un Baremo, como en los accidentes de automóviles, que vincule su aplicación a Jueces y Magistrados, y en el que se valoren las indemnizaciones que corresponden al ciudadano cuando sufra un accidente, o incidente, en su paso por Tribunales y Juzgados. Es decir, que el mal funcionamiento, las dilaciones indebidas, los errores judiciales, etc, con todo su espectro de circunstancias reales, fijen la correspondiente indemnización que será exigible ante el mismo Juzgado o Tribunal, sin necesidad de peregrinar por los diferentes estamentos estatales, en una especie de Vía Crucis, cuyo Monte del Calvario final son 3 céntimos de Euro, concedido a regañadientes, por haber pasado un mes de cárcel sin ton ni son. Se trata de una responsabilidad civil objetiva, de carácter extracontractual que, en modo alguno, es una cuestión personal contra el Juez o Magistrado.

Si compartes la intención de este Manifiesto adhiérete al mismo:

ajura-ong@terra.es

y difúndelo 
$\mathrm{Si}$, además, puedes enriquecer, con tus propuestas, su texto háznoslas llegar. Pretendemos, ante todo, un debate público hasta conseguir un proyecto de bases para la reforma y modificación de la LEY DEL JURADO PÚBLICO y, así, entre todos hacer campaña a favor de una NUEVA LEY DEL JURADO PÚBLICO QUE DEMOCRATICE LA JUSTICIA. 